\title{
Early acquisition responding on trials following different rewards and nonrewards'
}

\author{
J. M. BLOOM \\ BAYLOR UNIVERSITY COLLEGE OF MEDICINE ${ }^{2}$
}

Rat Ss were trained in the straight runway under a regular pattern of partial reward. Amount of reward and duration of nonreward were varied factorially. Responding in early acquisition on trials following the various rewards and nonrewards was fastest following large reward, slower following small reward, slower still following short nonreward, and slowest following long nonreward.

Several experiments (Bloom \& Capaldi, 1961; Capaldi \& Stanley, 1963; Capaldi, Turner, \& Wynn, 1962) have shown that running time in partially rewarded rat Ss is different on trials following reward (TFR) than on trials following nonreward (TFN). Early in training, the difference is such that running time on $T$ FN is slower than on TFR, regardless of whether the pattern of reward and nonreward is regular or irregular.

In the present experiment, this relationship was explored further to determine whether different amounts of reward and different durations of nonrewarded confinement would result in different running times on immediately succeeding trials.

Subjects

The Ss were 48 experimentally naive female rats purchased from the Holtzman Company, Houston, Texas. They were approximately 90 days old at the start of the experiment.

\section{Apparafus}

The apparatus was a straight runway 4 in. wide, $8 \mathrm{in.} \mathrm{high,} \mathrm{and} 6 \mathrm{ft}$. in length. It was constructed of wood and painted gray throughout except for the hinged covers and the final $4 \mathrm{in}$. of the floor of the alley, which were $1 / 4$ in. hardware cloth. The final $1-\mathrm{ft}$. section constituted a goal box, and it was separated from the rest of the runway by a gray metal guillotine door which was lowered once $S$ entered the goal area. The initial 1-ft. section of the runway contained a treadle which, when depressed by S's weight, started a 1/100 sec. standard electric timer which stopped when $S$ depressed a second treadle 4 in. long located immediately beyond the guillotine door.

The goal box contained a round gray metal foodcup 3 in. in diameter and 1.5 in. deep, which was divided into two equal sections by a gray wooden partition 1.5 in. high. The cup was mounted 1 in. above the floor of the alley at the end of the goal box so that when the cup was rotated on a pivot the partition was continuous with the wall of the goal box. Each portion of the food cup contained the reward, Grape Nuts cereai, equally often throughout the experiment.

Between trials, $S$ was confined in a large black wooden box.

\section{Procedure}

On days 1-10, the Ss were housed in groups of six and were fed Rockland Mouse Breeder Diet pellets for $1 \mathrm{hr}$. each day according to the approximate time that they were to receive the daily experimental trials. On day 11, the animals were placed in individual cages and fed at the same time as on previous days. On days 12-15, each $S$ was placed in the goal box for the first $5 \mathrm{~min}$. of the feeding period, during which time the foodcup was baited with Grape Nuts cereal.

On day 16, the first daily acquisition trials were begun. Group RnR received a 60 sec. reward of Grape Nuts cereal, a $10 \mathrm{sec}$. nonreward, and a $60 \mathrm{sec}$. reward each day, in that order, for 18 days. Group rNr was given similar training, except that rewarded trials were $10 \mathrm{sec}$. and nonrewarded trials $60 \mathrm{sec}$. Two other groups were trained under RNR and rnr.

The intertrial interval throughout training was 20 sec., and each $\mathrm{S}$ was fed for $1 \mathrm{hr}$. each day beginning about $15 \mathrm{~min}$. following the last daily trial.

Results

An inspection of the data showed that the early trials produced slower running on TFN and faster running on TFR, and this effect continued through block four except for a single point deviation in group mr on block two. Generally, running time decreased through block four. On blocks five and six, the curves for TFR and TFN began to show marked deviations in trend as a function of nonrewarded confinement, with $n$ groups continuing to respond slower on TFN than TFR, but with $\mathrm{N}$ groups running faster on TFN than TFR. Thus the $\mathrm{N}$ groups may be said to have learned the pattern, since TFN were always rewarded and TFR always nonrewarded.

An analysis of variance on the first four trial blocks showed that the Ss ran significantly faster on TFR than TFN $(F=15.24, d f=1 / 44, p<.01)$, and that running time decreased significantly over trial blocks $(F=29.20$, $\mathrm{df}=3 / 132, \mathrm{p}<.01)$. The block by pattern interaction was also significant $(F=6.01, \mathrm{df}=3 / 132, \mathrm{p}<.01)$, indicating that running time decreased over blocks of trials faster on TFN than TFR. It is of interest that the decrease on TFN was essentially negatively accelerated while that for TFR was S-shaped.

Figure 1 shows running times following the various trials in the form of gradients. The block by pattern interaction is clearly discernible. Additional analyses showed that running time on the four kinds of trials differed only on block one $(F=5.26, d f=3 / 90, p<.01)$. Discussion

The occurrence of pattern learning in the long 


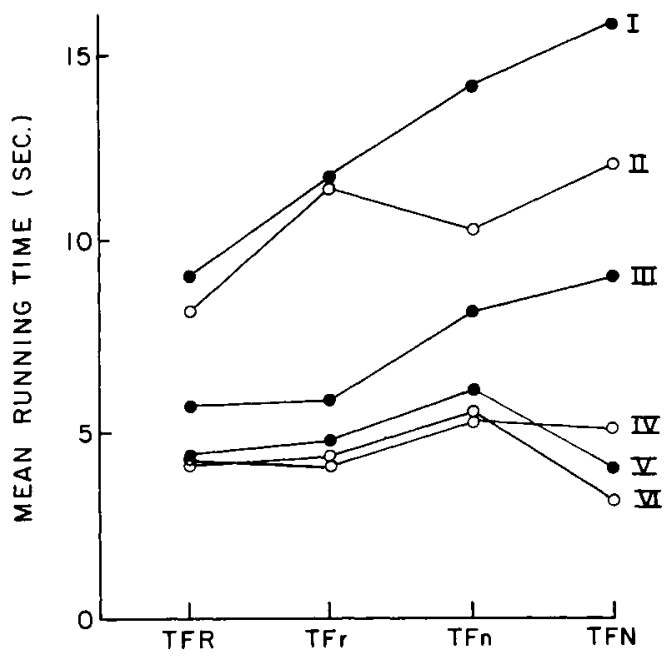

Fig. 1. Gradients of running time on trials following different rewards and nonrewards on trial blocks I through VI.

nonreward groups of the experiment was unexpected. Usually, more nonreward-reward transitions than were given here are required before pattern learning takes place (Bloom \& Capaldi, 1961; Capaldi \& Stanley, 1963); but there were procedural differences between the present investigation and previous ones (e.g., percentage and amount of reward) which may in part account for this finding. It is of interest that the $n$ groups did not show the effect. However, since pattern learning was far from complete, it would be unwise to attempt to draw conclusions about the development of pattern learning as a function of any of the variables under investigation.

With regard to the early trial effects, it seems clear that different amounts of reward and differentdurations of nonreward affect responding on the immediately succeeding trials. As in previous experiments, the Ss ran faster on TFR than TFN on the very first trial block. Also, as Fig. 1 shows, running time was fastest following large reward, slower following small reward, slower still following short nonreward, and slowest following long nonreward. The fact that this gradient appears without prior training indicates differences in unconditioned response strength for running following different amounts of reward and nonreward, and the effect is typical of stimulus dynamism (Hull, 1949).
Such findings support the stimulus aftereffects conditioning model, which assumes that reward and nonreward give rise to distinctive stimuli which remain functional and may be conditioned by reinforcement to the response on the succeeding trial (Bloom \& Smith, 1965; Capaldi, 1964). The present results indicate that different amounts of reward and nonreward produce distinctive stimulus aftereffects.

There are other aspects of the data which offer support for the aftereffects model. It was noted that running time on all trials decreased over trial blocks. Assuming that the growth of response strength is a function of reinforcement, then the decrease in running time on TFN is understandable since every nonreward is followed by reward. However, responses on TFR were never reinforced, and it may be assumed that the decrease in running time on TFR occurs because of the growth of generalized response strength.

Thus the growth rate for response strength should be typical of a conditioned response for TFN and a generalized response for TFR. Hovland (1937) found that these curves are negatively accelerated and S-shaped, respectively. Growth on TFN is generally negatively accelerated, and growth on TFR is clearly S-shaped. While such evidence is indirect, it nevertheless supports the assumption that conditioning of stimulus aftereffects is achieved through reinforcement.

\section{References}

Bloom, J. M., \& Capaldi, E. J. The behavior of rats in relation to complex patterns of partial reinforcement. J. comp. physiol. Psychol., 1961, 54, 261-265.

Bloom, J. M., \& Smith, N. F. Stimulus aftereffects of bar pressing. Psychon. Sci., 1965, 3, 23-24.

Capaldi, E. J. Effect of number of partial reinforcement training trials on resistance to extinction. Paper read at American Psychological Association meeting, St. Louis, 1962.

Capaldi, E. J., \& Stanley, Larry R. Temporal properties of reinforcement aftereffects. J. exp. Psychol., 1963, 65, 169-175.

Capaldi, E. J., Tumer, Lester, \& Wynn, William H. Decremental and facilitative effects in the straight-alley runway under partial reinforcement. J. comp. physiol. Psychol., 1962, 55, 545-549. Hovland, C. I. The generalization of conditioned responses. IV. The effects of varying amounts of reinforcement upon the degree of generalization of conditioned responses. J.exp. Psychol., $1937,21,261-276$.

Hull, C. L. Stimulus intensity dynamism (V) and stimulus generalization. Psychol. Rev., 1949, 56, 67-76.

\section{Notes}

1. The results herein reported formed a part of the author's doctoral dissertation.

2. Also at Houston State Psychiatric Institute. 